of the goods will be forthcoming so long as a demand exists, but once it is regarded as offensive-or shall we say indicative of a lack of good taste?--to wear such things as the wings, heads, feathers, or bodies of birds, the demand will cease and the trade, so far as this country is concerned, disappear. Herein, we think, lies a remedy far more effective than any Act of Parliament.

The University, St. Andrews, March 27 .

\section{The Physiology of Migrations in the Sea.}

THE flat-fishes of Northumberland in the immature condition migrate more or less inshore in summer and offshore in winter. Flounders are relatively static, plaice migrate offshore to the north-east and dabs to the south-east. The migration is not, as a rule, conspicuous, and, so far as the young stages are concerned, might be regarded as not taking place.

With approaching maturity, however, these three species migrate far to the north. The flounders for the most part reach the coast of Fife, and the plaice deeper water off the Forth and the Scottish coast to the north. The dabs do not appear to migrate so far to the north as the plaice, but we have a record of one that migrated so far as St. Andrews Bay. Fulton has shown that the Moray Firth plaice migrate to the north, and even to the Atlantic.

The migrations may be said, therefore, to be a series of seasonal inshore and offshore movements, followed by a marked contranatant journey for spawning. After spawning the spent fish resume the seasonal migrations, and become then, more obviously, summer inshore migrants.

We have thus plainly two factors at work: one external, which maty be associated with temperature, the other internal, which we at once conclude to be due to the action of an internal secretion. The seasonal migrations are obviously independent of the spawning migration, and may be said to be produced by hydrographical conditions and the contranatant ability of the fish. Under the influence of the spawning impulse fish migrate usually to a great, and sometimes to an immense, distance. The effect is strong enough to force the eel to descend from fresh water to the sea, and thence to mid-ocean, and to impel the salmon from the sea to the river, and, in spite of difficulties, to the spawning-ground.

The spawning migration is not always so plainly marked, but these considerations go to show that all fish migrations are of a similar character, a general seasonal series of movements affecting all, and a special migration under the dominating influence of an internal secretion or hormone, which, proceeding from the developing gonad, is carried by the blood to the nervous system. With reference to the species referred to above, it can be said that the hormone begins to exert its influence about autumn or the later months of the year, and continues its effect during the whole period of ripening. It is periodic in its manifestations, and the call, when it comes, is imperative. Only in special circumstances, as lack of water, say, in the river, can the spawning migration be said to be modified by hydrographical or other physical conditions. The distinction between the two kinds of migration must be clearly kept in view if we are to understand and appreciate the results of marking experiments. From, say, November to the spawning season mature plaice are contranatant migrants; after spawning they are denatant, or usually so, until the winter. The large number of records which have been accumulated, resulting

NO. 2633 , VOL. IO5] from the investigations of past years, should be reconsidered with this in mind.

It is interesting to observe that the only invertebrate of the migration of which we have direct proof behaves almost exactly like the plaice and the flounder. The common edible crab (Cancer pagurus) migrates inshore in summer and offshore in winter with the greatest regularity. Maturity impels the female to become a contranatant migrant. The females migrate from the Northumberland coast to the southern coast of the Firth of Forth, some of them still further to the north, even to the Moray Firth, the general results indicating a direct relationship between size and distance. The hormone is therefore secreted in the crab by the developing ovary, and it reacts in exactly the same way as that of the fish. The experiments have clearly proved that the migration does not occur until the winter before the season of spawning, and in this respect the crustacean and the fish are in agreement. It takes place during the offshore winter migration and in deep water, but the effect is differential, the male not migrating. It is not necessary for the male to migrate, as the migration takes place after pairing, even a year or two years after. This appears to indicate that the internal secretion is under control or may be withheld in response to evolutionary necessity.

Dr. Gurley, in the American Journal of Psychology (I902 and 1909), brought under review the indications of the intoxication of the central nervous system by internal secretions as explaining the spawning migrations of fresh-water fish in North America; so that the point is not new. We do not know very much about the internal secretions, but we know enough to be able to say that they act directly and quickly as an intercommunication between organs with or without reference to the nervous system. In the sea the effects are indicated by migration in the case of such animals as are capable of making migrations, but it is obvious that in many cases the internal secretions derived from the gonad have somatogenetic as well as mental effects, as in the development of secondary sexual characters.

The developing gonads of fish and the crab offer interesting material for the investigation of internal secretions by a biochemist. My main object, however, is to indicate that we already know the general facts and laws of migration, that marking must be done intelligently and the results read with due consideration of the laws, and more especially that the spawning migration is due to an intoxication of the central nervous svstem, and brings about a migratory result independent of temperature, salinity, and every other hydrographical condition.

Armstrong College, Newcastle-up March 30.

\section{Muscular Efficiency.}

WHEN muscular force is exerted, power is expended and fatigue is produced, even when the muscle remains stationary. Again, when no external force opposes the contraction of the muscle, physiological causes set a limit to the speed at which contraction can take place. In both cases the whole power expended is lost in so far as the production of useful work is concerned. When there is no velocity the power is used in maintaining the stress, and when there is no resistance, in maintaining a constant velocity. ${ }^{1}$

In all ordinary muscular operations both these sources of power leakage act simultaneously but in 1 This loss is independent of any power lost in the acceleration of the parts. 